\title{
Journal publishing in our connected world
}

Kian Keong Poh, FRCP, FACC

$\mathrm{H}$ appy New Year and welcome to 2019! This year marks my sixth as Editor-in-Chief of the Singapore Medical Journal (SM), and it has been a privilege to serve you in this capacity. Along with this privilege comes the responsibility to ensure that this journal keeps pace with the rapid developments in the field of medicine and biomedical science while maximising its impact and efficiency. It is my pleasure to report that the $S M$ J has continued to do well in 2018.

I would like to thank the Editorial Board members and editorial staff, whose dedication and hard work have kept the $S M$ J running smoothly on a daily basis. I am indebted to the hundreds of peer reviewers who have volunteered their time and expertise to ensure that only the best papers are accepted for publication. I must also thank our authors for submitting their major research to the $S M$ J - these works continue to define the quality and reputation of this journal.

Our collective efforts have led to excellent outcomes. Based on the 2017 Journal Citation Reports (JCR) published by Clarivate Analytics, ${ }^{(1)}$ the $S M$ J is in the third quartile of the Medicine, General and Internal category of the JCR and has achieved an impact factor of 1.08. This is a milestone for the journal and validates our continuous effort to expand the influence and reach of the $S M J .^{(2)}$ We have put an emphasis on topics relevant to Singapore and the region. ${ }^{(3)}$ Together with the strategies we have implemented to improve manuscript processing time, ${ }^{(4)}$ we can confidently look forward to an even better $S M J$ in the new year.

The emergence of the Internet era and digitisation of data has given rise to many changes in scientific publishing. One of these is peer-reviewed, open-access (OA) publishing that provides free access to online research. A large body of high-quality OA research is now available to a wide audience. Unfortunately, there has also been an alarming increase in predatory $O A$ journals and publishers, which bypass the business model of legitimate OA publishing. These typically require authors to pay high upfront publication fees without providing robust peer review, editorial or publishing services. ${ }^{(5)}$ Often, attempts by authors to withdraw their manuscripts are blatantly ignored or turned down. Bowman observed that these groups "market their 'services' through emails to scientists and faculty members, offering recipients the opportunity to publish articles in a new online peer-reviewed journal, to serve as a reviewer or editor of a new journal, or to speak or host a roundtable discussion at a conference, which may be described as 'global' or 'international'."'(6)

In recent years, the $S M$ J has encountered several cases of submitted manuscripts that had already been published in predatory journals, often without the authors' knowledge.
When contacted by our editorial office, the authors expressed shock, as they had not been asked to submit revisions or shown the final draft, nor had they been informed that their paper had been published. In fact, repeated communications to the journal office to withdraw their manuscripts had been met with silence. Unfortunately, due to potential issues relating to duplicate publication, we were unable to consider these manuscripts for re-publication in the $S M$ J, as the authors were unsuccessful in getting their articles taken down from the websites of these journals.

Predatory publishing undermines the credibility of peerreviewed scientific publishing. All stakeholders in the scientific community - publishers, authors, reviewers, universities and libraries - have a role to play in eliminating this scourge. For authors and reviewers, we advise you to keep yourselves well informed about the modus operandi of predatory journals, and exercise caution and vigilance when approached to submit papers to or be part of the editorial boards of OA journals. There are several tools and resources available to help researchers steer clear of predatory journals and publishers. Dr Jocelyn Clark, senior editor at PLOS Medicine and assistant editor at the BMJ, laid out a five-point plan, including looking up journals and publishers in Beall's List, a regularly updated 'blacklist' that also provides criteria for identifying predatory groups. ${ }^{(5)}$ Think Check Submit, an international, cross-sector initiative, provides a range of tools and practical resources to educate and help researchers identify trusted journals for their research. ${ }^{(7)}$ I believe that with the concerted efforts of the scientific community, we can eventually stamp out these unscrupulous business practices.

The Internet has also allowed editors and reviewers to assess and grade submitted articles to the $S M$ J, anytime and anywhere. In the past, as described by Prof Anthony DeMaria, immediate past Editor-in-Chief of the Journal of the American College of Cardiology, video conferences between editors took place in the wee hours of the day across nations (due to different time zones) to discuss the fate of each paper. Recent conversations with Prof Catherine Otto, Editor-in-Chief of Heart, touched on this practice as being no longer efficient. Instead, editors discuss matters online, through messages and emails. Indeed, this is also the practice for the $S M$ J. Internet separation in public institutions has recently resulted in some amount of inconvenience and inefficiency, not only for clinical care, but also for our editorial processes. But no matter what future challenges we face, we can overcome them by working smarter and together.

On behalf of the SMJ Editorial Board, I wish our reviewers, authors and readers a prosperous and successful 2019. Good health to all! 


\section{REFERENCES}

1. Clarivate Analytics Web of Science. Available at: https://clarivate.com/products/ web-of-science/. Accessed November 30, 2018.

2. Poh KK. Increase in impact factor for the SMJ. Singapore Med J 2018; 59:345.

3. Tay ELW, Ngiam JN, Kong WK, Poh KK. Management of severe aortic stenosis: the Singapore and Asian perspective. Singapore Med J 2018; 59:452-454.

4. Poh KK. A time for reflection and thanks. Singapore Med J 2018; 59:1.
5. Clark J. How to avoid predatory journals-a five point plan. In: The BMJ Opinion. Available at: http://blogs.bmj.com/bmj/2015/01/19/jocalyn-clark-how-to-avoidpredatory-journals-a-five-point-plan/. Accessed November 30, 2018.

6. Bowman JD. Predatory publishing, questionable peer review, and fraudulent conferences. Am J Pharm Educ 2014; 78:176.

7. Think. Check. Submit. Available at: https://thinkchecksubmit.org/. Accessed November 30, 2018. 